\title{
The Intervention and Regulation of Pornography: Internal Punishment, Negative Externality, and Legal Paternalism
}

\author{
Yen Lai $\mathbf{P}^{1 *}$, Dong $\mathbf{Y}^{2}$, Wang $\mathbf{M}^{3}$ and Wang $\mathbf{X}^{4}$
}

${ }^{1}$ Department of Translation and Interpretation National Changhua University of Education, Taiwan

${ }^{2}$ Faculty of Law, Chinese University of Hong Kong, Hong Kong

${ }^{3}$ Overseas Department, Xinhua News Agency, Beijing, China

${ }^{4}$ Faculty of Law, Chinese University of Hong Kong, Hong Kong

\begin{abstract}
This paper explores whether the intervention and regulation of pornography can be justified from the grounds of internal punishment, negative externality, and legal paternalism. Our investigations were based on questionnaires collected from students and visitors in a HK university. The results point to a severe build-in punishment, a weak perceived negative externality, and a weak legal paternalism associated with the consumption of pornography. Taken together, the intervention and regulation of pornography can not be substantiated on those grounds.
\end{abstract}

\section{JEL Classification: $\mathrm{K} 22$}

Keywords: Negative externality; Legal paternalism

\section{Introduction}

The social consequences of pornography have attracted research interests from a variety of academic disciplines, either from law scholars or social scientists from various disciplines. If the social consequences stemming from the consumption of pornography are grave, as some have claimed, then the regulation and intervention toward the consumption of pornography could conceivably be justified [1]. This paper explores two issues: whether regulation and intervention toward pornography are necessary, and if so, what would be the appropriate level of regulation and intervention. For the second issue, it is essential to build up benchmarks in relation to pornography such that the appropriate level of regulation can be pinpointed by referring to other closely related and regulated goods and services that are justified on the same policy rationale. In order to search for meaningful benchmarks, we started with relevant theoretical concepts. The theoretical underpinning of this research has been derived from the feminist claim that consumption of pornography breeds the discrimination toward women. Such discrimination toward women can be interpreted as a form of negative externality since women who suffered from discrimination are party outside the transactions of pornography. We designed questionnaire to test the severity of such negative externality in relation to other regulated goods and services that also suffer from negative externality. These questionnaires have been distributed to 136 students and visitors in a Hong Kong university campus, and collected for statistical analysis.

There are various social consequences associated with the consumption of pornography and feminist claims are just one of them. Current research suggests that pornography could lead to more incidences of rape, harassment and discrimination of women and the corruption of moral that eventually endangers marriage. These various researches have been sketched out in Chapter 13 of Sex and Reason by Richard A. Posner and a recent working paper by Todd Kendall [2]. According to Posner, the regulation of pornography will depend on a few factors: the social consequence it creates, the social value of pornography, the law enforcement costs, the difficulty of distinguishing socially valuable from socially valueless expression, and the free speech policy protected by the Constitution. Theory of social consequence is just one of those many pillars. There are three major social consequences: rape, harassment and discrimination, and corruption of moral. Our questionnaire is concerned only with the feminist theory of harassment and discrimination. Presumably, if consumption of pornography breeds discrimination toward women, the rational response of women would be a negative reaction toward anyone with such personal traits. Our questionnaire was designed to measure such negative reaction, if there is one. For example, if female reacts negatively toward someone addicted to pornography, as opposed to male, such claim would probably be true. However, we cannot conclude anything simply from sexual differential because such differential could exist in everywhere. Thus, it is imperative that such negative reaction be compared with other benchmarks, so that we obtain a relative, rather than absolute measure of sexual differential. If female demonstrates a more negative reaction toward someone with the habit of consuming pornography than male and such sexual differential is substantially larger in the case of pornography, taken together, these will imply female's rejection toward someone with that habit. Consequently, we could move one step forward toward confirming the feminist claim because such negative reaction could stem from a natural response from its discrimination effect. Of course, such negative reaction could also stem from other sources and further research will be required to pinpoint the exact cause. When comes to the selection of benchmarks, it is crucial to restrict the benchmark on goods and services that are closely related to the consumption of pornography. The possible hint, again, is suggested by the feminist claim. The discrimination toward women due to the consumption of pornography is essentially a negative external impact imposed on women because women are influenced in a negative way without ever getting involved in such transaction in the first place. Thus, it would make sense to focus on

${ }^{*}$ Corresponding author: Yen Lai P, Professor, Department of Translation and Interpretation, National Changhua University of Education, Taiwan, Tel: +886 4723 2105; E-mail: aniln@factltd.com

Received September 30, 2014; Accepted December 16, 2014; Published November 26, 2014

Citation: Yen Lai P, Dong Y, Wang M, Wang X (2014) The Intervention and Regulation of Pornography: Internal Punishment, Negative Externality, and Legal Paternalism. J Glob Econ 3: 128. doi:10.4172/2375-4389.1000128

Copyright: ( 2014 Yen Lai $P$, et al. This is an open-access article distributed under the terms of the Creative Commons Attribution License, which permits unrestricted use, distribution, and reproduction in any medium, provided the original author and source are credited. 
consumption of goods and services where negative externality is of great concerns. Overall, we selected smoking, drinking, and the consumption of marijuana and junk food as benchmarks because the regulations of these activities have been justified by negative externality as well. In addition, such benchmarks would also help to pinpoint the reasonable degree of regulation on pornography, as opposed to other relevant goods and services. Other things equal, the legal punishment should be proportional to the negative external impact based on the enshrined principle of proportionality. For example, if the consuming of pornography is perceived to be more socially damaging than the consuming of alcohol, the regulation toward pornography should presumably be tighter. Externality is something that occurs outside the market system and it provides justification for intervention and regulation. Before probing into the question of externality, we design our questionnaire in a way to address the internal punishments that have been incorporated within the system toward someone with such a habit. We are interested in evaluating the negative responses generated by consumption of pornography in order to gauge how severe the associated punishments have been incorporated within the system. Again, such measure would better be a relative one for precisely the reasons argued earlier. The upshot is: if someone who is addicted to pornography has already been severely punished within the social system, the justification for its intervention and regulation would be much weakened. After all, externality, could have, to a large degree, been internalized. Our ideal setting for inside the system punishment is workplace and marriage market. If the consumption of pornography, given that it is a known personal trait, generates very negative responses from work place and substantially reduces someone's chance of finding a mate, the build-in punishment within the system is already severe, and we will have to think twice before adding more regulations on top of that. In addition to externality and internal punishment, our questionnaire also addresses the issue of legal paternalism. If the society demonstrates a strong attitude of paternalism toward any social nuisance, there might be greater justification for enacting relevant laws to address such nuisance because a democratic society ideally should reflect what most people think and prefer. Whether any measure thereby enacted is actually welfare enhancing would be a different question. Again, the degree of paternalism toward the regulation of pornography is measured in relative terms, i.e. in relation to other closely related issues bridged through the concept of externality. In the following, section 1 discusses the theoretical concepts of negative externality, internal punishment, and legal paternalism and relevant policy considerations. Section 2 contains the analysis of questionnaire and the final conclusions are addressed in section 3. The original questionnaire is provided in Appendix $\mathrm{A}$ and the purposes of its design are explained in Appendix B.

\section{Theory: Negative Externality, Internal Punishment, and Legal Paternalism}

In this section, we explore the three possible justifications for the intervention and regulation of pornography: negative externality, internal punishment and legal paternalism. We discuss the relevant theoretical concepts and policy considerations that underpin each of these justifications.

\section{Negative externality}

Decriminalization of possession of small amounts of drugs has been proposed in the State of New York by Governor Andrew Cuomo. According to Governor Cuomo, 'the problem is the law' [3]. In September 2010, the then California Governor Arnold Schwarzenegger signed legislation that made possession of anounce of marijuana an infraction, previously a misdemeanor, punishable by a $\$ 100$ fine [4]. This has been followed by the statewide ballot of Proposition 19, which could have legalized marijuana and allowed local government to collect tax revenue from its sales, although it was defeated in November 2010 by a margin of $53.5 \%$ to $46.5 \%$ [5]. The regulation of marijuana has been severely criticized due to its ineffectiveness in the prevention of drugs and the high cost associated with it. In a September 17 2001 Business Week editorial, [6]. Nobel Prize Laureate Gary Becker advocated the deregulation of drugs. This echoed earlier suggestion by Harvard economist Robert Barro in his March 13, 2000 Business Week editorial [7].

When presenting their arguments, both Becker and Barro analyzed drugs issues on par with cigarettes and alcohol, both of which are related to negative externality on third parties. According to their views, the policy toward drugs should be emulated after the policy of alcohol and cigarettes, not the other way around. 'We seem to be moving on an inexorable path toward eventually managing tobacco the way we presently treat illegal drugs. Prohibition should have told us something' [8]. Instead of an outright ban, a substantial "sin" taxes should be imposed on the sales of these items so that government can collect tax revenue and use that revenue to decrease the consumer demand. 'In many nations, retail price of cigarettes, alcohol, and gasoline are several hundred percent higher than their whole sale prices, because of large "sin" taxes on them. The revenue collected from large taxes on drugs could be used to treat addicts and educate youngsters about the harmful effects of many drugs' [9].

In addition to alcohol, cigarettes, marijuana, they are still other issues where negative externality is of some concern. One much discussed policy by New York City is its ban on trans fats food. On December 5, 2006, it became the first city in US to ban trans fats food in restaurants [10]. A closely related policy issue is use of 'fat tax' to address the overweight problem. Again, it has been suggested that, such policy should be modeled after the policy of alcohol and cigarettes. According to Gary Becker, 'One proposal receiving some attention is to impose a tax on foods that contain high quantities of saturated fat in the hope of cutting down consumption of these foods. The basic law of demand states that a tax on saturated fat would raise the price of fatty foods, and thereby would reduce their consumption. A good analogy is with other "sin" taxes, such as the very heavy tax in most countries on cigarettes, or the large tax in many countries on alcoholic beverages' [11]. It appears that externality factor is in play, although only of minor concern, behind such policy consideration. 'Are public policy interventions then justified? A common affirmative answer relies on the fact that overweight people who get serious diseases use health resources that are partly financed by taxpayers. This argument has some merit because of heavy taxpayer involvement in health spending' [12].

'Sin' taxes are taxes that are imposed on items such as alcohol, drugs, and gambling as the consumption of these items is related to socially 'sinful' behaviors. A key issue is: what constitutes 'sin' in 'sin' tax? One possible answer is negative externality. If that is the case, then sin tax is precisely a Pigovian tax, a tax on goods and services that generate negative externality [13]. Indeed, one common feature shared by alcohol, cigarettes and gasoline is that they are all connected by negative externalities. Alcohol could lead to DWI, cigarettes create second hand smoke and gasoline creates air pollution. Regulations that are based sin tax are essentially a conservative idea, other liberal justifications, include legal moralism and legal paternalism, will be 
discussed in section 1.3. Based on an enshrined principle advocated by John Stuart Mill, 'government has no right to regulate private activity that does not have adverse effects on nonconsenting third parties' [14]. Mill's principle has been followed by libertarian such as Gary Becker and for libertarian that would be the only appropriate interpretation for sin taxes.

To sum up, the issues concerning drug, alcohol, cigarettes and fast food could all be bridged by negative externality. Since the feminist claim is essentially an externality argument, it would be appropriate to compare people's attitude toward pornography with other policy issues that are justified on the ground of negative externality. Through such comparison, we can evaluate the justification of externality argument that underpins the intervention and regulation of pornography.

\section{Productivity, internal punishment and social safety net}

An appropriate measure of productivity in the service sector can be found in Robert Barro's Business Week editorial, [15] which suggested 'the only meaningful measure of productivity is the amount a worker adds to customer satisfaction and to the happiness of co-worker.' A negative impact on one's productivity could imply grave consequences such as lower wage, as well as lower chance of retaining a job. In addition to negative impact on labor market, the impact on marriage market could be equally, if not more, important, as our research subjects were concentrated on young men and women in their 20 s and 30s. For them, finding a job and a mate are probably two of the biggest things in their lives.

Our basic idea is a social evolutionary one: if someone who is addicted to the consumption of pornography and such personal trait, once revealed, results in punishment from labor as well as marriage market, other things equal, his chance of surviving, or living well could be double jeopardized. It follows that there would be weaker ground for imposing regulation because adding costs on someone who is miserable or destitute would violate the fundamental spirit behind the design of social safety net.

\section{Legal paternalism}

'The only purpose for which power can be rightfully exercised over any member of a civilized community, against his will, is to prevent harm to others. His own good, either physical or moral, is not a sufficient warrant. He cannot rightfully be compelled to do or forbear because it will be better for him to do so, because it will make him happier, because, in the opinion of others, to do so would be wise, or even right' [16]. 'Harm to others' is a form of negative externality, and negative externality would be the only ground for intervention if Mill's principle has been followed.

However, H. L. A. Hart argued for a revised version of Mill's principle. According to Hart, physical good would be sufficient warrant, while moral good would not. The state may intervene on the ground of legal paternalism if individuals are likely to neglect their own best interests and the interference with their liberty is slight' [17]. The law requiring the wearing of seatbelt would be a case in point. Thus, a distinction can be drawn between legal paternlism and legal moralism, which is based on moral good. Overall, legal paternalism is more interventionist than Mill's principle, and is more well defined in its scope of intervention than legal moralism.

The boundary betwenn Mill's principle and legal paternalism has been further blurred by a new philosphy, soft paternalism or libertarian paternalism, proposed by Univeristy of Chicago behavior economist
Richard Thaler and legal scholar Cass Sunstein in their best selling book, Nudge: Improving Decisions about Health, Wealth and Happiness [18]. In short, libertarian paternalism is 'attempts to influence the choices of affected parties in a way that will make choosers better off,' [19] while preserving their choices to opt out. Its practical application can be illustrated through the design of default option. In some social scenarios, the default option can be designed in a way to improve the welfare of people, utilizing people's mindlessness while filing their paper works. For example, people could be mindless and subsequently find themselve ending up in the retirement saving plan simply because they forget to opt out on the relevant application forms. Of course, if they are altert enough, they could always exercise their option to opt out. The fact that people are mindless has been supported by certain evidences from behavioral sciences, especially psychology, that people could be myopic and could also act irrationally at times. In sum, libertarian paternalism is the third way of Mill's principle and legal paternalism, It lies to the left of Mill's principle and to the right of legal paternalism.

\section{The Analysis of Questionnaire}

We collected a total of 136 samples from the campus of the Hong Kong Polytechnic University on June 22, 2012. Our subjects had the option to answer the questionnaire in its English or Chinese version. We did not ask people to identify themselves whether they were Hong Kong Polytechnic University students, and some of them were obviously visitors or job seekers. Thus, it is more appropriate to define the population as the Hong Kong Polytechnic University community of students and visitors. These samples are non random as some questionnaires have been distributed to a group of friends in study lounge or student restaurant. For question 1 to 7 , there were 58 effective samples from male and 59 effective samples from female. Among the total of 117 effective samples, 81 are from the age group of 18 to 25,28 are fro the age group of 26 to 30 , and 8 from the age group of 31 to 40 . The sexual distribution of each age group is illustrated in Appendix C.

The following analysis was based on the mean score from each option. A score of 5 was assigned to scenario that was perceived to be the most negative, followed by $4,3,2$, and 1 . Thus, the higher the mean score, the higher would be its degree of negative impact. We then compared the mean score obtained from the pornography case and compare it to other scenarios. The plots of data and statistical distributions of question 1 to 7 have been illustrated in Appendix D.

Our main results are based on descriptive statistics, i.e. the comparison of mean scores instead of running $t$ test or regressions, which are more rigorous. However, the lack of quantitative rigor could somehow be compensated through the qualitative depth of our questionnaires. Some of our subjects were willing to spend as much as 20 to 30 minutes to fill out the questionnaires because they considered such ranking problems intriguing, and some of them even requested samples of our questionnaires as souvenirs. Some even stayed for further discussions. Thus, to some degree, our questionnaires strike a balance between quantitative data, which provides width, and cases, which concentrate on in-depth exploration.

\section{Question 1, 2 and 3: Internal punishment}

We will start with question 3 , which evaluates the negative impact on marriage market. The numbers inside the parenthesis indicate the mean score. The ranking in terms of the severity of negative impact for male is: marijuana (4.84), alcohol (3.19), cigarette (3.16), pornography (2.53), and junk food (1.28). In contrast, the ranking for female is: 
marijuana (4.81), alcohol (3.41), pornography (2.92), cigarette (2.78), and junk food (1.08). Thus, female does react in a more negative way toward potential spouse's consumption of pornography than male as pornography ranks ahead of cigarette and achieves a third place out of five. In terms of the female and male differential, taking the absolute value, the ranking of question 3 is: pornography $(0.39)$, cigarette $(0.38)$, alcohol (0.22), junk food (0.2), and marijuana (0.03). There is a strong sexual differential toward the consumption of pornography as female reacts much more negatively than male. The feminist claim appears to be supported by a strong negative reaction toward the consumption of pornography from female, as well as by a very different reaction from male. In addition, the sexual differential toward the consumption of cigarette is almost on par with pornography, suggesting that smoking could be another area where sexual divide is worthy of further investigations. The ranking obtained from question 1 for male is: marijuana (4.88), alcohol (3.45), pornography (2.84), cigarette (2.64), and junk food (1.19). The ranking for female is: marijuana (4.86), alcohol (3.19), pornography (3.17), cigarette (2.73) and junk food (1.05). Thus, overall, pornography moves up one spot from fourth place to third place for male and remains on 3rd place for female, in comparison with question 3 . As for the ranking from question 2 , for male it is: marijuana (4.84), alcohol (3.29), cigarette (2.98), pornography (2.62) and junk food (1.26), for female it is: marijuana (4.68), pornography (3.27), cigarette (3.08), alcohol (2.88) and junk food (1.08). The impact of pornography on colleague relationship appears to be low for male, as it ranks on fourth place, and high for female, as it surges to 2 nd place. Female reacts more negatively toward their colleagues who are addicted to pornography than their potential spouses. After all, if the purpose of marriage is to procreate, perhaps certain allowance can be given to someone with the habit of consuming pornography. In addition, in a work place setting, consumption of pornography could conceivably be associated with sexual harassment issue.

In terms of the female and male differential, again, taking the absolute value, the ranking of question 1 is: pornography (0.33), alcohol (0.26), junk food (0.14), cigarette (0.09), and marijuana (0.02). The ranking of question 2 is: pornography (0.65), alcohol (0.41), junk food (0.18), marijuana (0.16), and cigarette (0.1). Pornography attracts the highest sexual differential in both questions. Here, the sexual differential should be appreciated from a different perspective, as opposed to the result from question 3 , because the responses toward work place apply across genders. Still, the sexual differential toward consumption of pornography remains substantial. Again, the very different sexual responses on customer and colleague relationship are consistent with the feminist claim. If we take the average score of question 1 and 2 and obtain the overall impact on productivity, the ranking for male is: marijuana (4.86), alcohol (3.37), cigarette (2.81), pornography (2.73) and junk food (1.22), the ranking for female is: marijuana (4.77), pornography (3.22), alcohol (3.03), cigarette (2.91), and junk food (1.07). The statistical distributions of these scores are contained in Appendix E. Such ranking is the same for male on question 2. Thus, the overall impact on productivity has been dominated by male's reaction toward colleague relationship, while the second place ranking of pornography from female owes much to female's very adverse reaction toward colleagues with the habit of consuming pornography. The sexual differential toward perceived productivity is: pornography (0.49), alcohol (0.34), junk food (0.15), cigarette (0.1), and marijuana (0.09). The sexual differential in pornography persists as it still ranks in the first place. The negative impact on perceived productivity due to the consumption of pornography is low for male and high for female. Overall, consumption of pornography as a revealed personal trait receives negative reaction from female in work place as well as in marriage market. Both results are compatible with the feminist claim. Still, whether the feminist claim is actually true will hinge on further research. Finally, if we take the average scores of question 1 and 2 and average it again with question 3, we could obtain rankings of overall internal punishment, which gauge the average impacts on productivity and marriage. The ranking for male is: marijuana (4.85), alcohol (3.28), cigarette (2.98), pornography (2.63) and junk food (1.25), the ranking for female is: marijuana (4.79), alcohol (3.22), pornography (3.07), cigarette (2.84), and junk food (1.08). The statistical distributions of these scores are provided in Appendix E. Such orders are the same as the ranking in question 3 , which suggests that the rankings of internal punishment have been dominated by impacts on marriage market.

\section{Analysis of question 4 and 5: Negative externality}

In terms of negative reaction toward neighborhood, the rankings for male and female are the same: marijuana $(4.79 ; 4.66)$, alcohol $(3.48 ; 3.25)$, cigarette $(3.14 ; 3.08)$, pornography $(2.47 ; 2.8)$ and junk food $(1.12 ; 1.2)$. The sexual differential is highest on the consumption of pornography, which is on par with question 1,2 and 3 . As to the perceived undue influence on kids or nieces, the ranking for male is: marijuana (4.9), cigarette (3.1), alcohol (3.09), pornography (2.64), and junk food (1.28), and the ranking for female is: marijuana (4.75), cigarette (3.12), pornography (3.05), drinking (3.02), and junk food (1.07). The sexual differential is again highest on the consumption of pornography. When concerned with the next generation, female's distaste toward pornography is quite obvious. The rankings from the average scores of question 4 and 5 , a measure of overall negative externality, are the same for both male and female: marijuana (4.84; $4.7)$, alcohol $(3.28 ; 3.14)$, cigarette $(3.12 ; 3.1)$, pornography $(2.55 ; 2.92)$, and junk food $(1.2 ; 1.14)$. Pornography ranks low, only on fourth place. The fourth place ranking is the same for male in internal punishment ranking, and lower for female, who places pornography on third place in their internal punishment ranking. The externality justification for intervention and regulation toward pornography appears to be a weak one due to the low ranking of pornography, based on the average scores of question 4 and 5. A weak externality justification, together with severe internal punishment from the side of female, does not provide much justification for the intervention and regulation of pornography.

\section{Analysis of question 6 and 7: Paternalism}

Questions 6 and 7 were designed to gauge the attitude of legal paternalism. The rankings from question 6 are the same for both male and female: marijuana $(4.9 ; 4.81)$, alcohol $(3.22 ; 3.47)$, cigarette $(3.21$; $3.39)$, pornography $(1.97 ; 1.95)$ and junk food $(1.71 ; 1.37)$. The rankings from question 7 are also the same for both male and female: marijuana $(4.64 ; 4.41)$, cigarette $(3.31 ; 3.54)$, alcohol $(3.1 ; 3.2)$, pornography $(2.31$; $2.44)$, and junk food $(1.64 ; 1.41)$. The scopes of these two questions are relatively macro as compared with previous questions and it appears that male and female rankings converge when evaluated from such macro, or social perspective. In addition, the sexual differentials toward the consumption of pornography are relatively minor as compared with previous questions, which is another sign of male-female convergence on macro issues. The rankings from the average score of question 6 and 7 , which measure the overall attitude of legal paternalism, are the same for male and female: marijuana $(4.77 ; 4.61)$, cigarette $(3.26$; $3.47)$, alcohol $(3.16 ; 3.34)$, pornography $(2.14 ; 2.19)$, and junk food (1.67; 1.39). Pornography ranks low, only at fourth place. Overall, legal paternalism does not provide much of a justification toward the intervention and regulation of pornography. 


\section{Conclusions}

In our questionnaire, we designed seven questions to test the underlying rationale for regulation and intervention of pornography. We were interested on two issues: should there be regulation or intervention at all, and if so, what is the appropriate level of regulation or intervention. Our hypothesizing is based on the feminist claim, a theory that has been subject to severe criticism. We relied on the concept of negative externality to build up other benchmarks so that we could evaluate the appropriate level of regulation and intervention with respect to other goods and services that are also subject to, or could be subject to, regulation and intervention based on the same rationale. To our surprise, the feminist claim has been indirectly supported by two of our findings: first, female reacts more negatively toward someone who demonstrates the habit of consuming pornography in work place as well as in marriage market, and second, such negative responses are also very different from male. However, even though the feminist claim could be true, the very negative responses from female toward work place and marriage market do suggest severe build-in punishments within the system. Thus, even if female suffers from negative externality through male's transaction of pornography, such externality could have been internalized in labor as well as in marriage market. Indeed, social interactions are a web of various human interactions, and certain injustice, or unfairness suffered from a given interaction or transaction could very well be compensated through other different links. A severe internal punishment, together with weak supports from negative externality and legal paternalism, altogether implies a very weak justification toward the regulation and intervention of pornography.

\section{Appendix A: The Questionnaire}

1. Imagine that you have a legal trouble. Someone introduces you a solicitor who might be able to sort out your trouble. However, by accident, you also happen to know that he/she has developed a 'bad' habit in his personal life. Which of the following personal trait would create the most negative image on him/her such that you would be very uncomfortable to hand over your case to him/her?

a) drinking

b) smoking

c) consuming marijuana

d) consuming pornography

e) consuming a great deal of junk food

2. Imagine you are someone's colleague, which of the following personal traits would affect your willingness to team up with him/her?

a) drinking

b) smoking

c) consuming marijuana

d) consuming pornography

e) consuming a great deal of junk food

3. Imagine you are soon to be engaged with or married to someone. Before doing that, you discover your love one has been indulged in some 'bad' habit, which of the following personal trait would most affect your willingness to marry him/her?

a) addicted to alcohol b) addicted to cigarettes

c) consuming marijuana regularly

d) consuming pornography

e) consuming a great deal of junk food

4. Imagine you live in flat in a multi-story building, which of the following characteristics are the worst nightmare that you could find in your next door neighbor?

a) drinking

b) smoking

c) consuming marijuana

d) consuming pornography

e) consuming a great deal of junk food

5. Imagine that your beloved young teenage niece (or kid, if you have one), introduces you his/her best friend. You learn by accident that this friend has a 'bad' habit. Which of following habit would worry you most such that he/she might generate bad influence on your beloved niece/kid?

a) consuming alcohol

b) consuming cigarettes

c) consuming marijuana

d) consuming of pornography

e) consuming a great deal of junk food

6. In your opinion, which of the following activities is most damaging to someone's physical health once it has been developed into a habit?

a) consuming alcohol

b) consuming cigarettes

c) consuming marijuana

d) consuming of pornography

e) consuming a great deal of junk food

7. Imagine you have some extra money to spend and you have determined to spend it on a foundation that is committed to a social cause. Which of the following type of foundation would be most effective in safeguarding people's physical health, which is of your utmost concern? Please rank each of the following activities.

a) Anti alcohol campaign and relevant education program

b) Anti smoking campaign and relevant education program

c) Anti drug campaign and relevant education program

d) Anti pornography campaign and relevant education program

e) Anti junk food campaign and relevant education program

\section{Appendix B: The Design of Questionnaire}

This questionnaire was designed to evaluate the regulation toward pornography, in order to verify if such regulation could be justified on the ground of negative externality, internal punishment, or legal paternalism. Questions 1, 2 and 3 were designed to gauge the degree 
Citation: Yen Lai P, Dong Y, Wang M, Wang X (2014) The Intervention and Regulation of Pornography: Internal Punishment, Negative Externality, and Legal Paternalism. J Glob Econ 3: 128. doi:10.4172/2375-4389.1000128

Page 6 of 6

of internal punishment, question 4 and 5 were designed to gauge the degree of negative externality, and question 6 and 7 were designed to measure legal paternalism associated with the consumption of pornography.

\section{The design of question 1,2 , and 3}

The first two questions attempt to gauge the negative impact of pornography on productivity, where productivity is measured in terms of customer satisfaction as well as effectiveness of team work. The first question addresses the impact of pornography on customer relationship and the second question addresses the impact of pornography on co-worker relationship. If the consumption of pornography breeds discrimination toward women, female workers would be reluctant to deal with or team up with someone with such personal trait. Together, the satisfaction from customer and the effectiveness of team work constitute a definition of productivity. Our questionnaire was designed to gauge the attitude of subjects, thus, we would be testing on 'perceived productivity' rather than the actual productivity. The third question measures the negative response toward potential mate due to his or her consumption of pornography. The basic idea is: if negative impact brought about by consumption of pornography is sufficiently large that it has been effectively punished within the system, such as reducing the chance of keeping a job, or/and the chance of finding a mate, there would be less justification of adding more punishment within the legal system since the penalty could have been largely internalized, in one way or another.

\section{The design of question 4 and 5}

The next two questions attempt to evaluate the possible negative external effect of pornography. As mentioned earlier, this is a perceived negative externality rather than actual negative externality. If the perceived external negative impact associated with addiction in pornography is huge relative to other regulated items, this might provide a justification for legal regulation on pornography. If not, the justification could not be substantiated on the ground of externality.

\section{The design of question 6 and 7}

The next two questions were designed to gauge the attitude of 'paternalism.' Legal paternalism is the type of paternalism that is concerned with citizen's physical well being. If people are concerned with physical health associated with the consumption pornography, there might be a legal justification, i.e., legal paternalism, for enacting relevant laws.

\section{References}

1. Baumol JW (1972) On Taxation and the Control of Externalities. American Economic Review. 62: 307-322.

2. Barro R (2000) To Beat Colombia's Guerrillas Legalize Drugs in the US Business Week.

3. Barron L, Strauss M (1989) Four Theories of Rape in American Society, A State-Level Analysis, Yale University Press.

4. Becker GS (1999) Bribe Third World Parents to Keep Their Kids in School. Business Week.

5. Becker GS (2001) It's Tim to Give up the War on Drugs. Business Week.

6. Becker GS (2006) Taxing Fact, The Becker-Posner Blog.

7. Kendall T(2006) Pornography, Rape and the Internet,unpublished manuscript.

8. Kristol I (1971) Pornography, Obscenity and the Case for Censorship, New York Times.

9. Kutschinsky B (1970) Studies on Pornography and Sex Crimes in Denmark. NytfraSamfundsvidenskaberne, eksp, DBK.

10. Mill JS (1859/1991) On Liberty in John Stuart Mill: On Liberty and Other Essays. John Gray ed. Oxford University Press.

11. Posner RA (1992) Sex and Reason. Harvard University Press.

12. Posner RA (2006) The New York City's Ban on Trans Fats The Becker-Posner Blog.

13. Posner RA (2006) The Trans Fats Ban, The Becker-Posner Blog.

14. Singer $P$ (2006) Homosexuality is Not Immoral Peter. Project Syndicate.

15. Thaler RH, Sunstein CR (2009) Nudge Improving Decisions about Health, Wealth and Happiness.

16. Wildmon DE (1986) The Case Against Pornography. Victor Books.

17. For relevant discussions, see Homosexuality is Not Immoral, Peter Singer, Project Syndicate.

18. Thaler RH, Sunstein CR (2010) Nudge: Improving Decisions about Health, Wealth and Happiness, Penguin Book, New York.

19. Willis LE (2012) When Nudges Fail: Slippery Defaults Page 1162 of Nudge. 